\title{
Quasi-decadal Salinity Fluctuations in the Labrador Sea*
}

\author{
Robert W. Houghton and Martin H. Visbeck \\ Lamont-Doherty Earth Observatory, Columbia University, Palisades, New York
}

(Manuscript received 26 January 2000, in final form 5 June 2001)

\begin{abstract}
The quasi-decadal salinity fluctuations in the upper $300 \mathrm{~m}$ of the Labrador Sea are investigated by partitioning all available salinity station data since 1948 by region and bottom depth. There are major freshwater anomalies in the early 1970s (the Great Salinity Anomaly), mid-1980s, and early 1990s. These vary in amplitude throughout the region, being least on the shelf and greatest over the slope region near the Labrador Current. The Labrador Sea cannot be considered a simple conduit for freshwater anomalies originating in the East Greenland Current. There is evidence that local processes modulate the anomaly. The freshwater anomalies in the Labrador Current are approximately twice as large as those in the East Greenland Current. The Baffin Island Current flowing southward through the western Davis Strait is the only local source of freshwater with sufficient volume to account for this increase. The propagation speed, $2-3 \mathrm{~cm} \mathrm{~s}^{-1}$, of the anomaly along the Labrador Sea margin is much less than the advection speed indicating a highly damped system. The connection of the North Atlantic Oscillation (NAO) with these quasi-decadal salinity fluctuations is most obvious in the Labrador Sea interior, where increased surface buoyancy flux during positive NAO drives deep convective mixing and thus terminates the fresh surface anomalies. Less clear are the processes by which NAO-forced changes of lateral freshwater flux modulate the salinity along the margin. The authors propose a feedback mechanism where, during years of low wind speed, freshwater accumulates offshore of the slope front in the surface layer. The increased upperlayer buoyancy prohibits further mixing, and low salinities persist.
\end{abstract}

\section{Introduction}

The origin of the quasi-decadal fluctuation of upper ocean water properties in the North Atlantic has been the object of a number of investigations. These can be divided into two approaches: consideration of sea surface temperature (SST) fluctuations and consideration of upper ocean salinity and sea ice variations.

The basin-scale structure and coherence of the quasidecadal SST fluctuations was first identified by Deser and Blackmon (1993) using EOF analysis of the Comprehensive Ocean-Atmosphere Data Set (COADS) data. The EOF mode with quasi-decadal variability had a tripole structure with a center of action east of Newfoundland near the boundary separating the subpolar and the subtropical gyres, a weaker out-of-phase center in the western subtropical gyre, and a broad, weak, and inphase region in the eastern tropical Atlantic centered off northwest Africa. A corresponding pattern of wind (Deser and Blackmon 1993: Kushnir 1994) and latent heat flux (Cayan 1992) anomalies lead to the suggestion

* Lamont-Doherty Earth Observatory Contribution Number 6270.

Corresponding author address: Dr. Robert W. Houghton, LamontDoherty Earth Observatory, Columbia University, P.O. Box 1000, 61 Route 9W, Palisades, NY 10964-8000.

E-mail: houghton@1deo.columbia.edu that these SST fluctuations are the ocean response to variations of the atmospheric forcing due to the North Atlantic Oscillation (NAO) (Visbeck et al. 1998).

In the subpolar gyre, and especially in the Labrador Sea, the quasi-decadal SST fluctuation is accompanied by an in-phase salinity fluctuation (i.e., cold-fresh; warm-salty) that extends to 200-300 m or approximately the penetration depth of the seasonal cycle (Houghton 1996; Reverdin et al. 1997). These cannot be generated solely by latent heat flux. Instead they represent changes in the relative proportions of cold, fresh Arctic Water and the warmer, saltier North Atlantic subpolar water.

The low salinity event observed in the Labrador Sea in the early 1970s has been designated the Great Salinity Anomaly (GSA) by Dickson et al. (1988). They traced its "origin" to an outflow of Arctic Water through Fram Strait into the East Greenland Current in the late 1960s. The salinity anomaly was then observed with subsequent time lags at Fylla Bank on the west Greenland coast, the Seal Island/Hamilton Bank section on the Labrador coast (Fig. 1) where the freshwater anomaly was estimated to be $2000 \mathrm{~km}^{3}$, past the Grand Banks and Ocean Weather Station Charlie $\left(42^{\circ} 45^{\prime} \mathrm{N}, 36^{\circ} 30^{\prime} \mathrm{W}\right)$, and then into the northeast North Atlantic. They inferred a propagation speed of $3 \mathrm{~cm} \mathrm{~s}^{-1}$ in the cyclonic subpolar gyre. Subsequent propagating freshwater anomalies in 


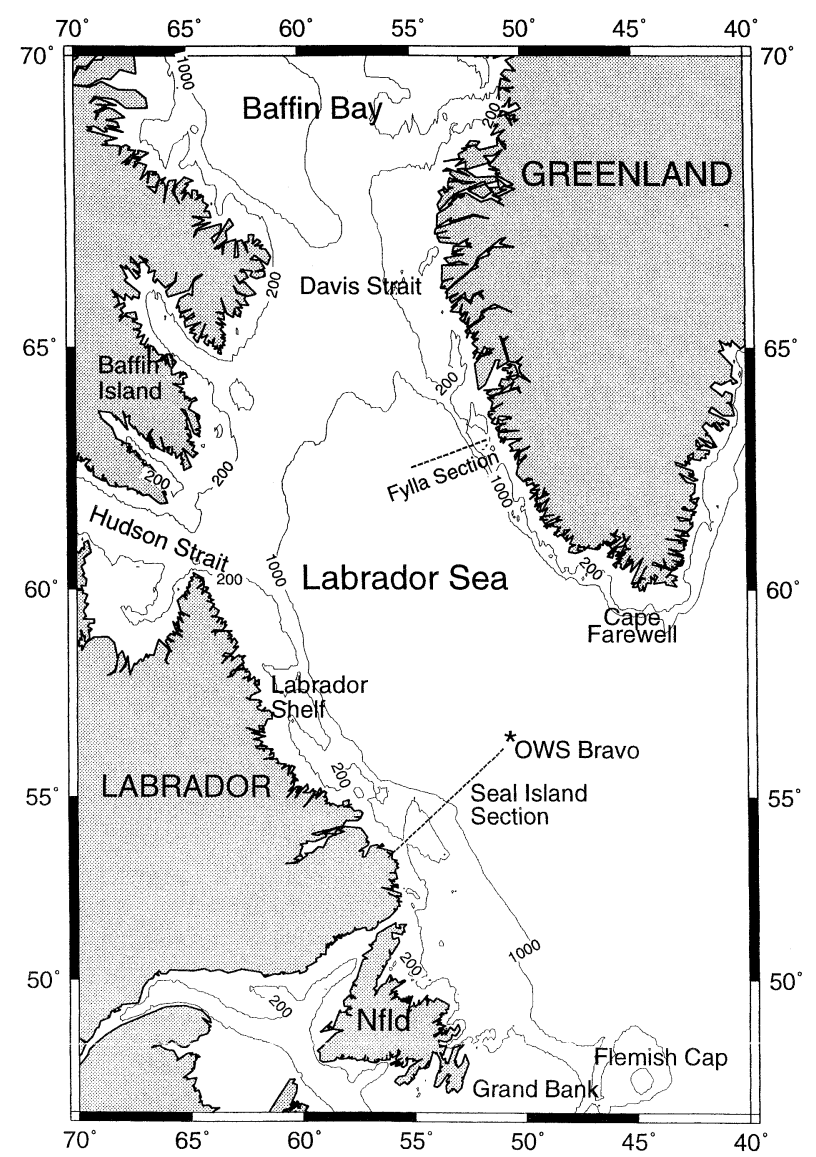

FIG. 1. Map of Labrador Sea region showing location of OWS Bravo and some of the frequently sampled sections.

the 1980s and 1990s have been identified by Belkin et al. (1998).

Reverdin et al. (1997) conducted an analysis of low frequency temperature and salinity fluctuations using all available data in the North Atlantic from 1948 to 1990. The first two EOF modes of the interannual salinity anomalies integrated to $300-\mathrm{m}$ depth had a phase shift between their centers of action consistent with an eastward propagation in the subpolar gyre. Corresponding modes of temperature deviations were coherent with salinity in the western subpolar gyre but not in the eastern portions. The NAO was in phase (a positive index corresponds to stronger wind and colder, fresher water) at zero lag with the decadal variability at OWS Charlie that lagged the signal near Labrador by approximately two years.

The quasi-decadal salinity fluctuations in the Labrador Sea have been associated with two distinct processes. The first is advective: the propagation in the subpolar gyre of an Arctic Water anomaly whose origin may be Fram Strait or the Canadian archipelago (Belkin et al. 1998). The second is stationary: the spatially coherent wind forcing by the NAO that modulates the surface buoyancy flux (Dickson et al. 1996), the con- vective mixing in the interior of the Labrador Sea (Khatiwala et al. 2002), the export of water from the Arctic Ocean (Hilmer and Jung 2000), and perhaps the strength of the gyre circulation in the Labrador Sea (Han and Tang 2001, manuscript submitted to J. Geophys. Res.) Is the apparent simultaneity of these two processes in the Labrador Sea (there are only three events to evaluate) merely a coincidence or does it represent a fundamental coupling of ocean advection and local atmospheric forcing?

We present here the results of an analysis of all available hydrographic data within the Labrador Sea to examine in detail the spatial and temporal variability of the salinity in the upper $300 \mathrm{~m}$. The objective is to evaluate freshwater sources required to generate the observed freshwater anomalies and to see whether there is evidence of local processes that would force, or at least modulate, the anomaly and thus require a revision of the view that the anomaly is a simple advective process. Within the limits imposed by the data distribution, we will partition the data in order to assess the magnitude and timing of the salinity anomaly throughout the Labrador Sea.

\section{Data}

The salinity data were derived from the Canadian Hydro Database for the northwest Atlantic (north of $35^{\circ} \mathrm{N}$, west of $42^{\circ} \mathrm{W}$ ), compiled and maintained by the Bedford Institute of Oceanography (http://www.mar.dfo-mpo.gc. $\mathrm{ca} /$ science/ocean/data.html\#database). This database includes the National Oceanographic Data Center (NODC) hydrographic database with additional Canadian data, especially along the Labrador coast. From consideration of the temporal distribution of these data (Fig. 2) we confine our analysis to data from 1948 through 1997. The spatial distribution of the data included in this analysis is shown in Fig. 3. The data are partitioned into three groups based on bottom depth $(h)$ and designated by color, blue (b): $h$ $<500 \mathrm{~m}$; green $(\mathrm{g}): 500<h<2000 \mathrm{~m}$; red (r): $h>$ $2000 \mathrm{~m}$. We use these color designations in the text; for example, the green data in box B is identified as $\mathrm{B}(\mathrm{g})$. The objective is to distinguish coastal from interior regions of the Labrador Sea and to highlight the Labrador Current, which is centered over the slope (green) region. Subsequent editing removed obvious outliers and stations where the water depth is less than $20 \mathrm{~m}$.

The geographical partitioning of the data, shown in Fig. 3, is a compromise of competing requirements. The first is to remove the annual cycle, whose amplitude and phase vary throughout the Labrador Sea, from the data as accurately as possible. The second is to isolate regions with historically repeated sampling such as the Fylla section on West Greenland [box F(b $+\mathrm{g})$ ], OWS Bravo at $56.5^{\circ} \mathrm{N}, 51^{\circ} \mathrm{W}$ [box $\mathrm{B}(\mathrm{r})$ ], or the Seal Island section [box $\mathrm{B}(\mathrm{b}+\mathrm{g})]$. Finally, we seek to identify regions of interest as potential freshwater sources: the East Greenland Current [box G(b $+\mathrm{g})$ ], outflow from 


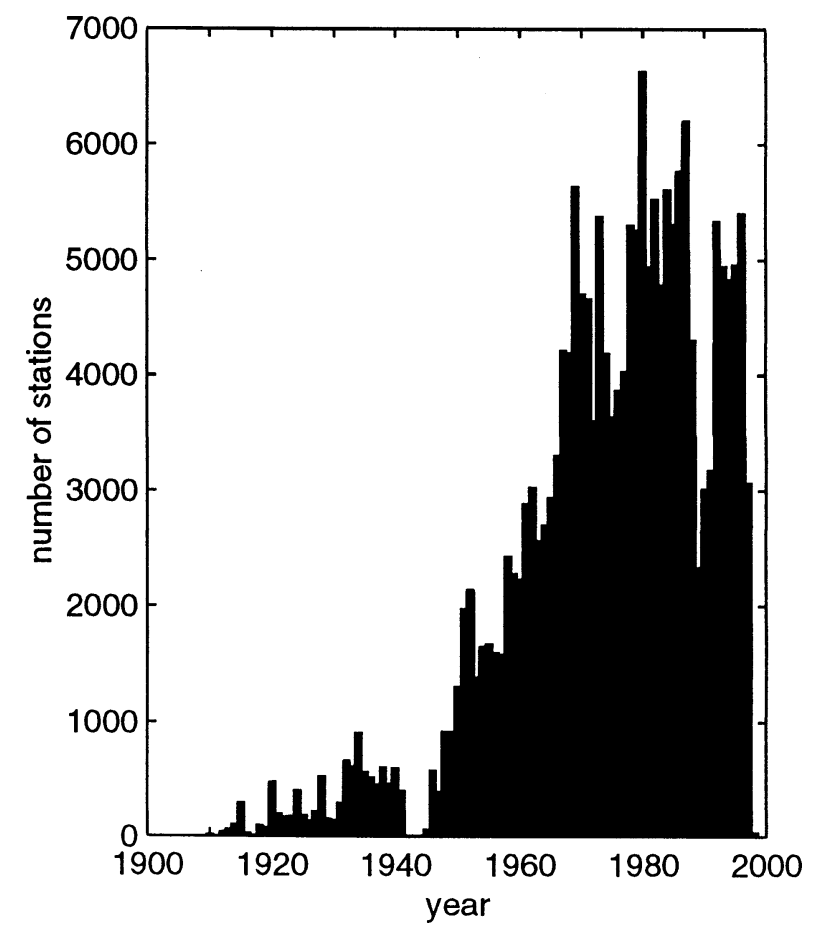

FIG. 2. Yearly distribution of hydrographic stations in the Labrador Sea from the Canadian Hydro Database used in this study.

Baffin Bay [box D $(b+g)]$, and the outflow from Hudson Bay [box $\mathrm{C}(\mathrm{b})]$. The number of stations within each region (Table 1) precludes finer spatial resolution. In fact, for subsequent analysis some of the regions as noted above were combined to increase the quantity of data.

There is considerable variation in the temporal distribution of the data within each box (Fig. 4). For instance, at OWS Bravo, box B(r), there was regular year round sampling only for 1964-74. The seasonal ice cover precludes observation during winter and spring in the northwest Labrador Sea. The data were so sparse in box $\mathrm{G}$ that even after combining $\mathrm{b}$ and $\mathrm{g}$ there was a gap during the late 1970 s and early 1980 s that could not be filled by interpolation.

The data analysis will focus on the quasi-decadal sa- linity anomalies of the upper water column. Were the data distributed evenly in time, annual anomalies could be derived from simple mean values for each year. However, given the irregular temporal distribution and the fact that in the upper $100 \mathrm{~m}$ the amplitude of the annual cycle is greater than the quasi-decadal (Houghton 1996), it is essential to calculate the deviations from the climatological mean. At each station the salinity at standard depths was subtracted from a monthly climatological value derived from data distributed over at least 10 years. Annual anomaly time series were constructed in several ways, which by inspection appeared to be equivalent. First, average monthly anomalies were derived from the individual station anomalies and then these were averaged into yearly anomalies. Since some boxes had sparse or virtually no winter data, separate anomalies were calculated for winter (January-June) and summer (July-December). Alternatively, anomalies were derived from a simple mean of all the data within a seasonal or annual interval. Inspection of the resulting time series, smoothed using a filter with weights proportional to $1-2-1$, showed no significant difference at quasi-decadal timescales. Below 100-m depth it was possible to generate equivalent time series by simply averaging all data to get an annual average.

\section{Results \\ a. Freshwater anomalies}

Our analysis will consider the salinity variations integrated to 300-m depth (Fig. 5) below which the quasidecadal fluctuation is negligible (Houghton 1996; Reverdin et al. 1997). These are calculated from data at depths 20, 50, 100, 200, and $300 \mathrm{~m}$ with the annual mean added when the anomaly data are used. Gaps up to three years are closed by linear interpolation and then the time series are smoothed with a 1-2-1 filter. It is difficult to specify the noise level given the uneven data distribution throughout the region. The number of stations averaged to produce an annual mean ranges from 5 to 20 . The standard error of this mean ranges from approximately 0.1 to 0.2 , so in the filtered time series multiyear variations of greater amplitude are robust, es-

TABle 1. The total (1948-97) stations with salinity data from the Canadian Hydro Database for the regions shown in Fig. 2 and used in this study; $h$ is depth (m).

\begin{tabular}{|c|c|c|c|c|}
\hline & $\begin{array}{c}\text { Blue } \\
20<h<500\end{array}$ & $\begin{array}{c}\text { Green } \\
500<h<2000\end{array}$ & $\begin{array}{c}\text { Red } \\
h>2000\end{array}$ & Total \\
\hline A & 5339 & 1274 & 373 & 6986 \\
\hline B & 2992 & 985 & 3741 & 7718 \\
\hline $\mathrm{C}$ & 1105 & 876 & 301 & 2282 \\
\hline D & 437 & 778 & 1 & 1226 \\
\hline $\mathrm{E}$ & 1958 & 389 & 0 & 2347 \\
\hline $\mathrm{F}$ & 880 & 653 & 516 & 2049 \\
\hline $\mathrm{FC}$ & 5507 & 3258 & 665 & 9430 \\
\hline GB & 12087 & 705 & 49 & 12841 \\
\hline Total & 30678 & 9231 & 6396 & 46305 \\
\hline
\end{tabular}




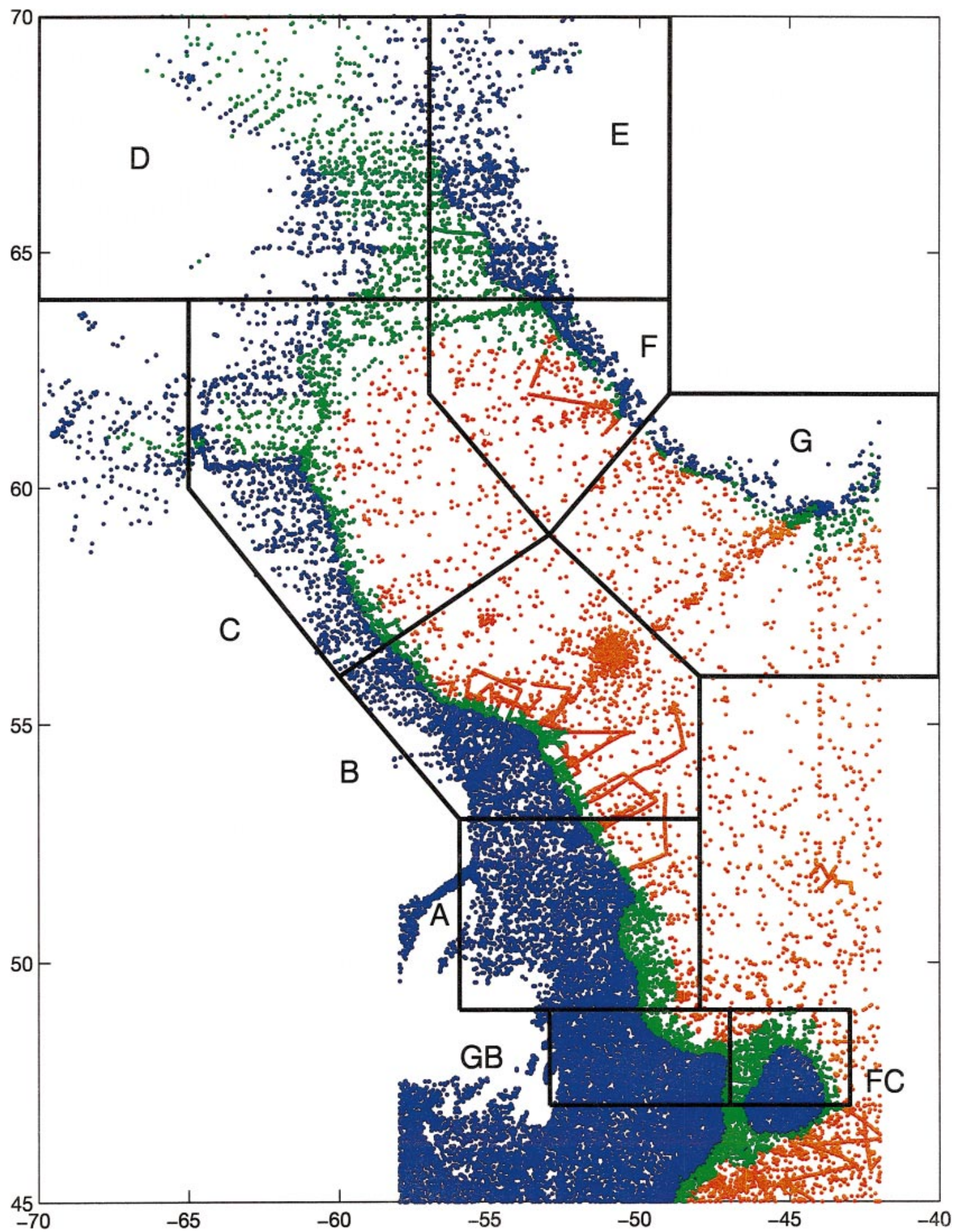

FIG. 3. Partitioning of data by geographical regions and by bottom depth: blue $<500 \mathrm{~m}, 500 \mathrm{~m}<$ green $<2000 \mathrm{~m}$, and red $>2000 \mathrm{~m}$.

pecially along the Labrador and Newfoundland margins where the data are more dense. We also varied the geographical partitioning of the data to confirm the robustness of the time series shown in Fig. 5, especially for $\mathrm{C}(\mathrm{g})$ and $\mathrm{F}(\mathrm{g})$. In Fig. 5 salinity time series are positioned at their approximate geographical location to assess more easily the spatial coherence of the salinity anomalies in the upper water column.

There are distinct differences in the time series of salinity variation along the margin, over the slope, and 

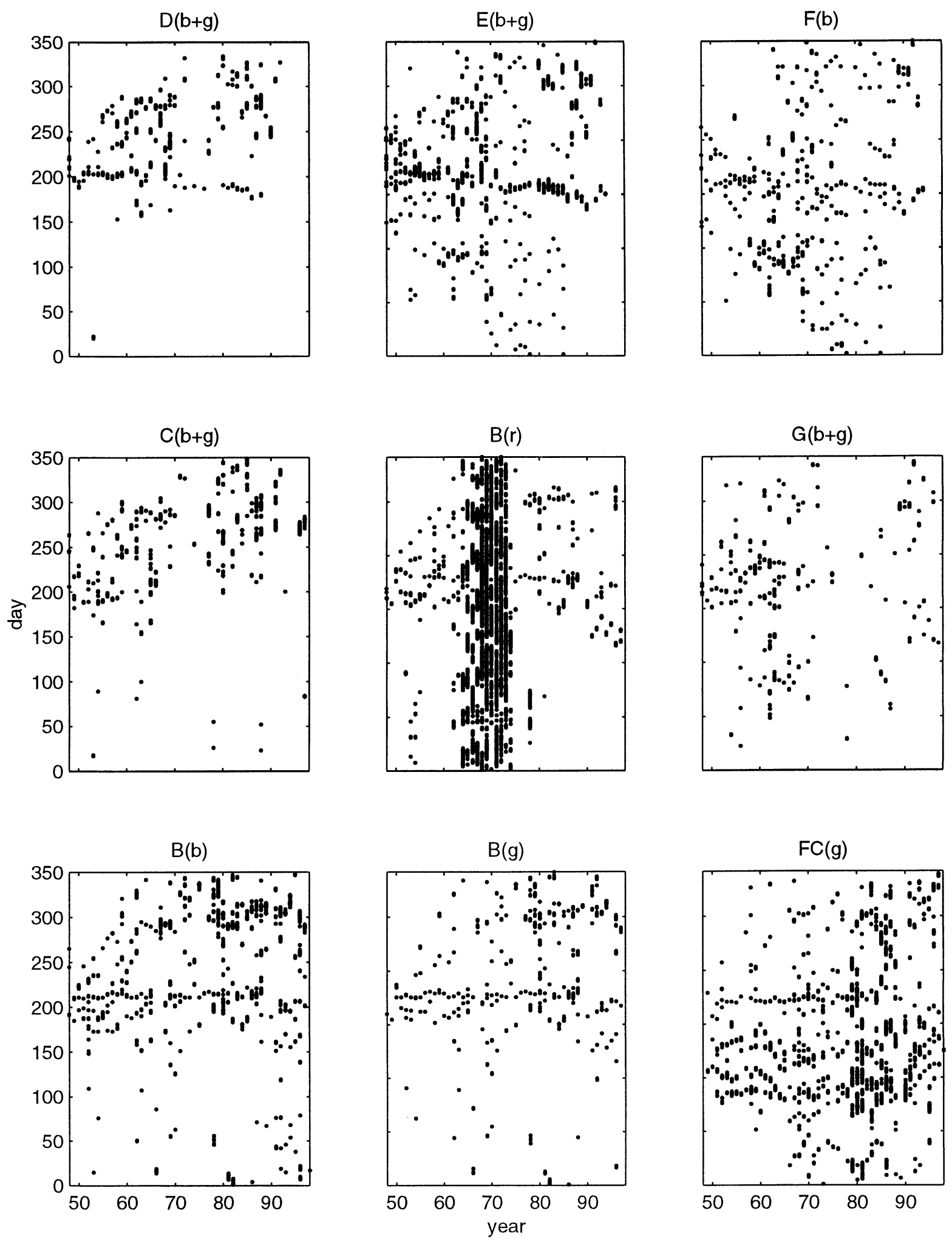

FIG. 4. The yearday distribution of hydrographic data in selected regions. 


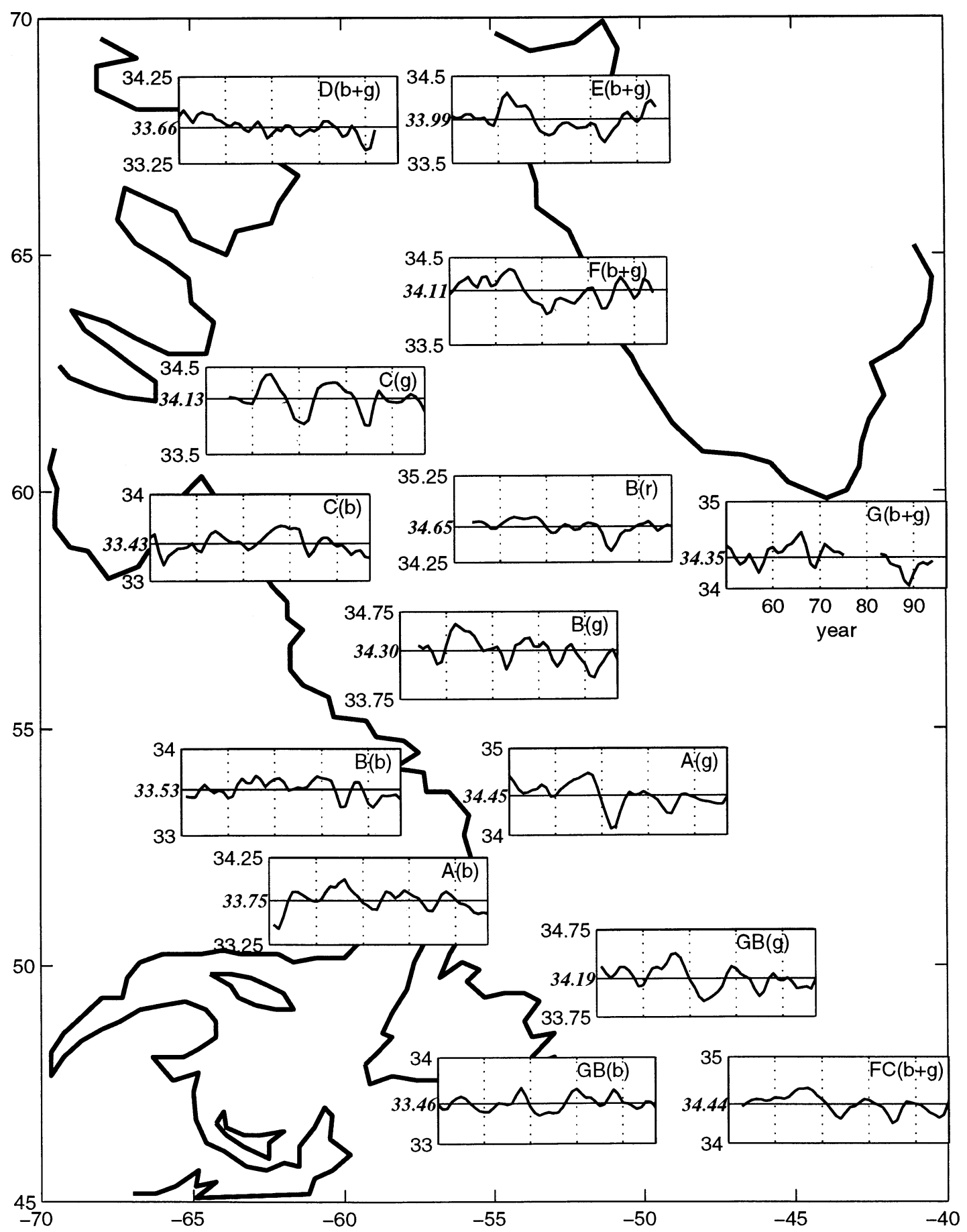

FIG. 5. Low-passed (1-2-1 filter) time series of the integrated $(0-300 \mathrm{~m})$ salinity for selected regions in the Labrador Sea. The vertical scale is the same for each graph, although the interval changes. The timescale, shown under $\mathrm{G}(\mathrm{b}+\mathrm{g})$, is the same for all graphs. The record mean salinity is given by the horizontal line.

in the interior of the Labrador Sea. The largest and most regular salinity fluctuations occur over the slope on the western margin of the Labrador Sea. Quasi-decadal fluctuations are virtually absent over the shelf along this margin. The only significant fluctuations that are ob- served there, at $\mathrm{B}(\mathrm{b})$ and $\mathrm{C}(\mathrm{b})$ in the $1980 \mathrm{~s}$ and $\mathrm{B}(\mathrm{b})$ and $\mathrm{F}(\mathrm{b})$ in the 1990s, are due to changes at depth, $\sim 100$ $\mathrm{m}$, and not at the surface. Salinity variations on the eastern inflow side of Davis Strait, $\mathrm{E}(\mathrm{b}+\mathrm{g})$, are similar to $F(b+g)$ to the south. The outflow on the western 
side of the strait, $\mathrm{D}(\mathrm{b}+\mathrm{g})$, is distinctly different with a record-long freshening trend and no quasi-decadal fluctuations, except perhaps in 1990.

The salinity variation in the interior of the Labrador Sea is represented by $\mathrm{B}(\mathrm{r})$, which includes OWS Bravo data. This time series is equivalent to that presented by Lazier (1995). The time series produced when anomalies from all of the "red" data in all boxes throughout the Labrador Sea are averaged is qualitatively similar. The relative magnitude of the salinity fluctuations in the interior is different from those over the slope. For example, over the slope the freshening in the 1970s is greater or the same magnitude as in the 1980s, while in the interior the 1980s anomaly is much greater the 1970s anomaly. At depth, $\sim 400 \mathrm{~m}$, salinity fluctuations in the interior have the opposite sign, suggesting, as described in detail by Lazier (1980), that deep convective mixing processes are involved.

Over the Labrador slope the peak-to-peak extreme salinity values for $\mathrm{C}(\mathrm{g}), \mathrm{B}(\mathrm{g})$, and $\mathrm{A}(\mathrm{g})$ range from 33.8 to $34.6 \mathrm{psu}$. These values are intermediate to the record mean value of $33.6 \mathrm{psu}$ on the shelf and 34.7 psu in the interior. The front separating coastal and interior water is located over the slope region. Therefore, the large salinity fluctuations in this region could be generated by displacements of this front rather than by changes in the water properties on either side. This will be considered in detail in section $3 f$.

The time-space lag of the salinity fluctuations along the margin of the Labrador Sea is shown in Fig. 6. Here the location of the salinity fluctuation is assigned to the centroid of the data distribution in each box, and the distance is calculated along the slope margin starting at Cape Farewell. The year of the fluctuation is estimated from inspection of the raw, unfiltered data. Both the time of the start of the dominant multiyear freshening trend in the 1960s and the time of the salinity minimum for the subsequent major quasi-decadal fluctuations are shown. The straight lines are least squares fits to the data. They indicate a cyclonic propagation around the Labrador Sea margin with a speed of 2.8 and $2.1 \mathrm{~cm}$ $\mathrm{s}^{-1}$ for the 1970s and 1990s, respectively. This speed is significantly less than advection speeds, which from the trajectories of drifters drogued at $15 \mathrm{~m}$ averaged around the entire margin (Cuny et al. 2002) is approximately $20 \mathrm{~cm} \mathrm{~s}^{-1}$ or from moored current meter data averaged over the upper $300 \mathrm{~m}$ of the Labrador Current (Lazier and Wright 1993) is greater than $15 \mathrm{~cm} \mathrm{~s}^{-1}$. The propagation of the 1980s event is less certain. There is no signal at box $G$ because of a gap in the data. The event occurs almost simultaneously from box C to GB. A least squared fit to all the data gives a speed of 5.1 $\mathrm{cm} \mathrm{s}^{-1}$. In contrast, the onset of the freshening in the early 1960s does not propagate cyclonically around the Labrador Sea. It occurs first at B and C with G and FC lagging by 4 and 5 years respectively.

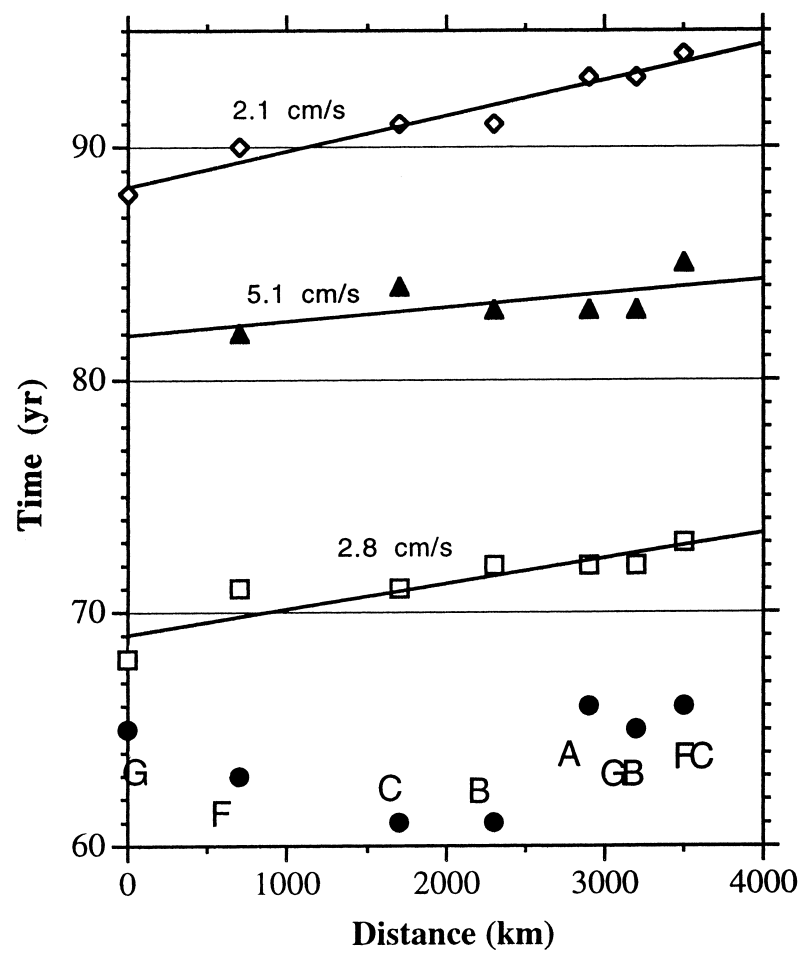

FIG. 6. Space-time lag of freshwater events in the Labrador Sea. Distance is calculated along the shelf break, with the origin at Cape Farewell. Solid circles denote the onset of freshening in the 1960s. The remaining symbols denote the salinity minimum of the subsequent quasi-decadal fluctuations. The propagation speed is inferred from the least squares linear fit to the data.

\section{b. Freshwater sources}

A motivation for this study was to examine the potential role of freshwater outflow through Davis Strait, connecting the Labrador Sea and Baffin Bay, as a freshwater source for the low salinity anomalies in the subpolar gyre. From a review of all existing data, Loder et al. (1998) demonstrated that the inflow through Davis Strait is the dominant annual mean freshwater source in the Labrador Sea. They estimated the annual mean freshwater flux, relative to $34.8 \mathrm{psu}$, to be $29 \mathrm{mSv}\left(10^{-3}\right.$ $\mathrm{Sv}: \mathrm{Sv} \equiv 10^{6} \mathrm{~m}^{3} \mathrm{~s}^{-1}$ ) around Cape Farewell from eastern to western Greenland, $120 \mathrm{mSv}$ through Davis Strait, and $29 \mathrm{mSv}$ out of Hudson Strait. Local freshwater runoff is $1.6 \mathrm{mSv}$ from West Greenland and $5.7 \mathrm{mSv}$ from Labrador. The freshwater flux due to precipitation evaporation over the Labrador Sea is $40 \mathrm{~cm} \mathrm{yr}^{-1}$ (Walsh and Portis 1999), which is equivalent to $13 \mathrm{mSv}$. Thus, the flow through Davis Strait provides approximately $60 \%$ of the mean annual freshwater flux into the Labrador Sea.

\section{c. Salt deficit}

In their analysis of the GSA Dickson et al. (1988) estimated the salt deficit associated with the passage of this freshwater anomaly through the Labrador Sea in 
TABLE 2. Calculated freshwater anomaly (FWA) around the margin of the Labrador Sea for the three quasi-decadal events evident in Fig. 5. Given are the flux, time duration, and average $(0-300 \mathrm{~m})$ salinity anomaly used in the calculation as described in the text.

\begin{tabular}{|c|c|c|c|c|c|c|c|c|c|c|}
\hline \multirow[b]{2}{*}{ Region } & \multirow[b]{2}{*}{$\begin{array}{l}\text { Flux } \\
(\mathrm{Sv})\end{array}$} & \multicolumn{3}{|c|}{ Early 1970s } & \multicolumn{3}{|c|}{ Mid-1980s } & \multicolumn{3}{|c|}{ Early 1990s } \\
\hline & & $\begin{array}{c}\text { Time } \\
(\mathrm{yr})\end{array}$ & $\Delta S$ & $\begin{array}{c}\text { FWA } \\
\left(10^{3} \mathrm{~km}^{3}\right)\end{array}$ & $\begin{array}{l}\text { Time } \\
(\mathrm{yr})\end{array}$ & $\Delta S$ & $\begin{array}{c}\text { FWA } \\
\left(10^{3} \mathrm{~km}^{3}\right)\end{array}$ & $\begin{array}{l}\text { Time } \\
(\mathrm{yr})\end{array}$ & $\Delta S$ & $\begin{array}{c}\text { FWA } \\
\left(10^{3} \mathrm{~km}^{3}\right)\end{array}$ \\
\hline $\mathrm{G}(\mathrm{b}+\mathrm{g})$ & 5 & 4 & 0.1 & 1.8 & & & & 4 & 0.1 & 1.8 \\
\hline $\mathrm{F}(\mathrm{b}+\mathrm{g})$ & 5 & 5 & 0.075 & 1.6 & 4 & 0.1 & 1.7 & 4 & 0.1 & 1.7 \\
\hline $\mathrm{C}(\mathrm{g})$ & 7 & 5 & 0.145 & 4.4 & 5 & 0.17 & 5.2 & & & \\
\hline $\mathrm{B}(\mathrm{g})$ & 7 & 4 & 0.13 & 3.2 & 5 & 0.11 & 3.4 & 5 & 0.11 & 3.4 \\
\hline $\mathrm{A}(\mathrm{g})$ & 7 & 5 & 0.16 & 4.9 & 5 & 0.09 & 2.8 & & & \\
\hline $\mathrm{GB}(\mathrm{g})$ & 6.5 & 5 & 0.09 & 2.6 & 5 & 0.12 & 3.4 & 5 & 0.08 & 2.3 \\
\hline $\mathrm{FC}(\mathrm{b}+\mathrm{g})$ & 2 & 5 & 0.1 & 0.9 & 5 & 0.11 & 1.0 & 5 & 0.08 & 0.7 \\
\hline
\end{tabular}

the following way: Using seven hydrographic sections across Hamilton Bank just north of the Seal Island section on the Labrador shelf taken between July 1971 and July 1976 and assuming 1976 to be near normal (Trites 1982), they calculated a salt deficit over the upper 400 $\mathrm{m}$ for stations extending out to approximately the 2000$\mathrm{m}$ isobath. The depth average salinity anomaly peaked at $\Delta S=-0.6$ in July 1973. Assuming that $5 \mathrm{~Sv}$ of the Labrador Current transport originated from West Greenland they inferred a total salt deficit integrated over a 2-yr period (1971-73) of $72 \times 10^{9}$ metric tons, which is equivalent to $2000 \mathrm{~km}^{3}$ of freshwater. This value was their benchmark for the magnitude of the GSA of the 1970s.

Results from an equivalent calculation using the time series in Fig. 5 are given in Table 2. The calculation requires several crude approximations but is still instructive. The transport values taken from Loder et al. (1998) are estimates of the transport of water with salinity $\leq 34.8$ psu along the margin of the Labrador Sea. Since the filter applied to the time series will broaden the anomaly signals by $2 \mathrm{yr}$, the time interval used is $4-5 \mathrm{yr}$ centered at the salinity minimum. The average salinity decrease, $\Delta S$, is calculated within that interval. Although crude, these calculations do show a coherent structure. The magnitude of the three quasi-decadal freshwater events is approximately constant. The magnitude of the salt deficit along West Greenland, $\sim 1700$ $\mathrm{km}^{3}$, is approximately half of that observed along the Labrador slope, $\sim 4000 \mathrm{~km}^{3}$, which is in turn approximately twice that calculated by Dickson et al. (1988) for the GSA. Although $\Delta S$ on the Labrador shelf at $\mathrm{C}(\mathrm{b})$ and $\mathrm{B}(\mathrm{b})$ in the $1980 \mathrm{~s}$ is comparable to that observed on the slope at $\mathrm{G}(\mathrm{g})$ and $\mathrm{B}(\mathrm{g})$, these correspond to a relatively small freshwater anomaly since the transport on the shelf is less than $1 \mathrm{~Sv}$.

In the interior of the Labrador Sea the salt deficit is calculated in a different way. Here the flow is much weaker (Cuny et al. 2002) so that, instead of a freshwater anomaly advecting through the region, we envision a freshwater flux into the interior from the low salinity margins that first accumulates, then is mixed to depth by the intense convective mixing events before being flushed out of the system (Lazier 1980; Khatiwala and
Visbeck 2000). The rapid increase in salinity following the anomalous freshening is the result of this mixing event. To estimate the magnitude of the salt deficit we apply the peak salinity anomaly to the volume of the interior. Estimating the area of the interior (red area in Fig. 3) to be $0.6 \times 10^{6} \mathrm{~km}^{2}$, the volume of the upper $300 \mathrm{~m}$ is $180 \times 10^{12} \mathrm{~m}^{3}$. From the time series of the salinity of the red portions of boxes A, B, C, F, and G, which is qualitatively similar to $\mathrm{B}(\mathrm{r})$ but slightly smaller in amplitude, we have a salinity decrease of $0.14,0.20$, and 0.05 for the $1970 \mathrm{~s}, 1980 \mathrm{~s}$, and 1990s, respectively. This implies a freshwater anomaly of 700, 1000, and $250 \mathrm{~km}^{3}$, respectively. Thus, the freshwater anomaly in the Labrador Sea interior is approximately $20 \%$ of the anomaly observed over the Labrador slope. The total freshwater anomaly throughout the Labrador Sea is then approximately $5000 \mathrm{~km}^{3}$. Even though the crude approximations required for this calculation could easily contribute to an error in this value of up to $50 \%$, it will be used as a benchmark when considering potential freshwater sources.

\section{d. Freshwater fluxes}

We now consider potential sources of freshwater to account for the quasi-decadal salinity anomalies observed in the Labrador Sea. We require sources capable of delivering $5000 \mathrm{~km}^{3}$ of freshwater in 4 years. This is equivalent to $4 \mathrm{~m}$ over the entire Labrador Sea or a mean freshwater flux of $40 \mathrm{mSv}$. For the annual mean the major source of freshwater into the Labrador Sea is the outflow from Baffin Bay, the Baffin Island Current, through the western side of Davis Strait. The flux is estimated to be $120 \mathrm{mSv}$ (Loder et al. 1998), so a $30 \%$ increase would be required if this were the sole source of the anomaly.

The only significant freshwater source for which the time variation is monitored is the outflow of Hudson Bay through Hudson Strait. The time dependence of this outflow (Fig. 7) is derived from the combined river discharge into Hudson Bay. The runoff record shows a trend of decreasing flow since 1965 with a 7-yr-long pulse of increased flow centered at 1985 . However, the volume of this pulse is approximately $300 \mathrm{~km}^{3}$, and this 


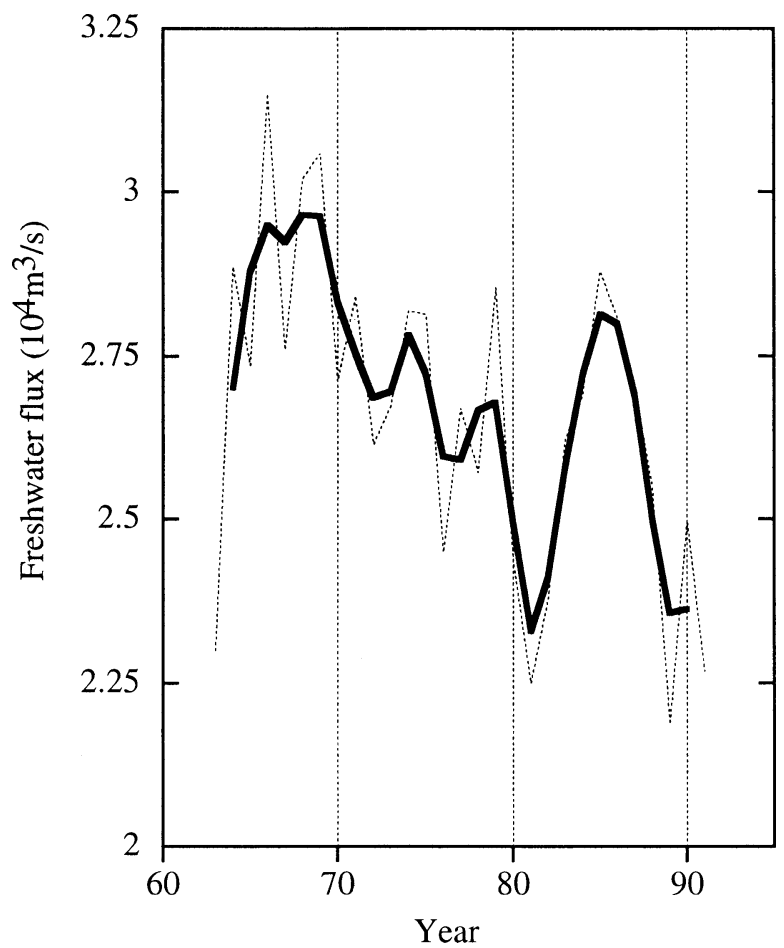

FIG. 7. The flux $\left(\times 10^{4} \mathrm{~m}^{3} \mathrm{~s}^{-1}\right)$ of Hudson Bay freshwater runoff. The dashed lines are annual averages; dark line is smoothed with a 1-2-1 filter. (Data courtesy R. Pettipas, K. Drinkwater, and S. Prinsenberg, Bedford Institute of Oceanography, Dartmouth, Nova Scotia, Canada.)

is much too small to make a significant contribution to the freshwater anomalies observed in the Labrador Sea. All other terrestrial freshwater sources are even smaller.

The contribution of precipitation minus evaporation, though difficult to measure, is also thought to be small. Walsh and Portis (1999) using National Centers for Environmental Prediction (NCEP) reanalysis data estimate a 40-yr annual mean $P-E$ in the Labrador Sea of approximately $40 \mathrm{~cm}$, which is equivalent to a freshwater flux of $13 \mathrm{mSv}$. This is comparable to the $50 \mathrm{~cm}$ of freshwater required to produce the annual salinity variation observed at OWS Bravo (Lazier 1980). However, because the local precipitation is greatest in winter while the annual salinity minimum is in late summer, Lazier (1980) suggested that the freshwater in the Labrador Sea interior is derived instead by lateral exchange from the margin.

At OWS Bravo Lazier (1980) estimated that the GSA freshening during 1967-72 required the accumulation of $1.7 \mathrm{~m}$ of freshwater, or $33 \mathrm{~cm} \mathrm{yr}^{-1}$. During this time period Walsh and Portis (1999) estimated a deviation from the annual mean of $\Delta(P-E) \approx-5 \mathrm{~cm} \mathrm{yr}^{-1}$. In the late $1970 \mathrm{~s}$, when a positive salinity anomaly was observed (Fig. 5), they calculated $\Delta(P-E) \approx+5 \mathrm{~cm}$ $\mathrm{yr}^{-1}$. Thus, the surface moisture flux was both too small and out of phase to be a factor in the observed quasidecadal salinity fluctuations.

\section{e. Sea ice}

The connection between increased sea ice extent and freshwater anomalies in the Iceland/Greenland and Labrador Seas has been explored by Mysak and Manak (1989). Although the two are correlated, the causal link is ambiguous. Is the freshwater anomaly due to sea ice meltwater or is the greater sea ice extent due to the increased stratification that suppresses vertical mixing of heat? The fact that freshwater anomalies lead the sea ice anomalies (Mysak et al. 1990; Marsden et al. 1991) suggests that the latter is more likely the case. Sea ice extent anomalies were observed to propagate from the Greenland Sea into the Labrador Sea (Mysak et al. 1990) coincident with the GSA of the 1970s, and this could be interpreted as a flux of freshwater via the sea ice or a surface expression of the freshwater anomaly in the water column underneath.

The volume of freshwater sequestered in sea ice can be estimated from North Atlantic sea ice coverage data that extends from 1953 to 1990 (Chapman and Walsh 1993). The sea ice extent in the Baffin Bay/Labrador Sea has a mean seasonal range from a late summer minimum of $30 \times 10^{4} \mathrm{~km}^{2}$ to a spring maximum of $224 \times 10^{4} \mathrm{~km}^{2}$ or a variation of $194 \times 10^{4} \mathrm{~km}^{2}$. There are positive sea ice extent anomalies in 1971-73 and 1983-85 coinciding with the freshwater anomalies. The largest positive sea ice extent anomaly recorded in 1984 was $41 \times 10^{4} \mathrm{~km}^{2}$ (Agnew 1993). We estimate the equivalent freshwater volume in the following way. Empirical orthogonal function (EOF) analysis of the interannual variability of the sea ice extent (Deser et al. 2001) indicates that these fluctuations are centered just south of Davis Strait. Here the mean ice thickness is approximately $1.5 \mathrm{~m}$ (Ice Climatology Services 1992), so this maximum sea ice extent anomaly corresponds to a freshwater volume of $615 \mathrm{~km}^{3}$. But since this anomaly represents a fluctuation of only $20 \%$ from climatology, certainly less than the accuracy of the ice thickness estimates, the ice volume anomalies derived from sea ice extent anomalies are crude and even the sign could be in doubt.

If the sea ice melts where it was formed, it delivers no new freshwater to the region. However, if the anomalous sea ice extent represents a steady-state melting line of ice transported into warmer water it could deliver a flux of new freshwater. For example, consider ice moving south out of Davis Strait into warmer water at the $3000-\mathrm{m}$ isobath. If sea ice $1 \mathrm{~m}$ thick moves at $0.1 \mathrm{~m}$ $\mathrm{s}^{-1}$ across an $800-\mathrm{km}$ front, as it melts it would supply approximately $400 \mathrm{~km}^{3}$ of freshwater in 60 days. Three continuous years of this freshwater transport could contribute $20 \%-30 \%$ of the observed freshwater anomalies in the Labrador Sea.

Likewise, there is a potential flux of sea ice from East Greenland around Cape Farewell during heavy ice years. Assuming this ice to be $1 \mathrm{~m}$ thick, extending $200 \mathrm{~km}$ south of Cape Farewell, and moving at $0.2 \mathrm{~m} \mathrm{~s}^{-1}$, it 


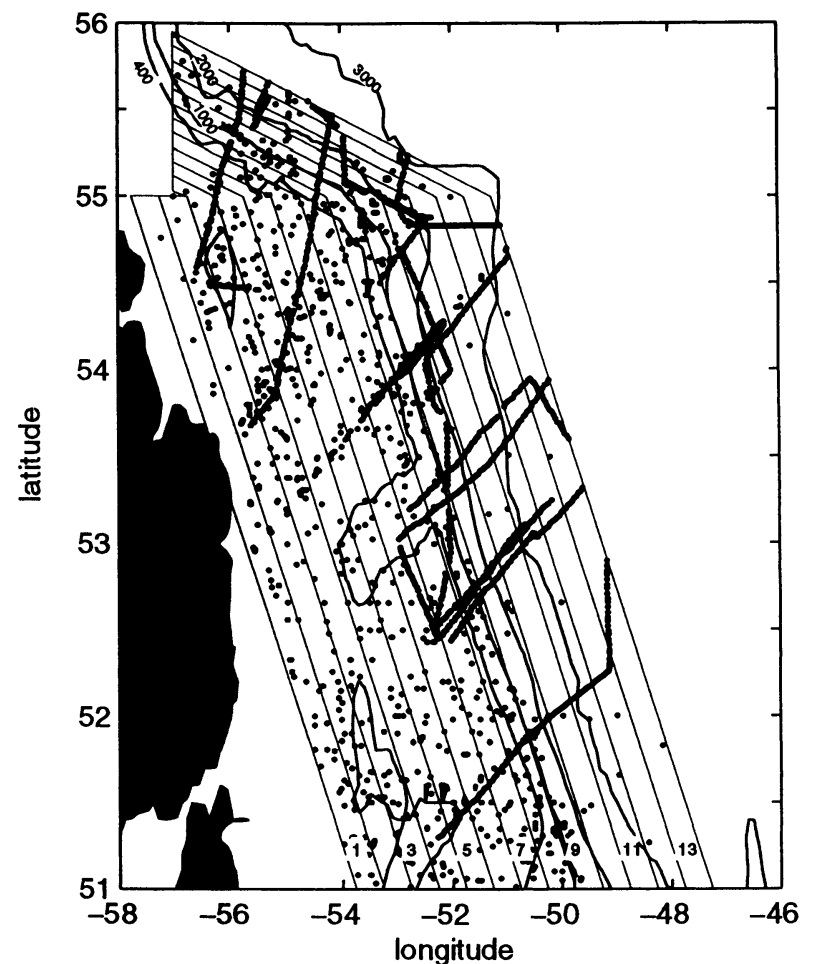

FIG. 8. Map of the grid used to partition the data into boxes 1-13 across the Labrador shelf/slope region. Also shown are bottom isobaths and the distribution of the data used in the calculation.

would deliver approximately $200 \mathrm{~km}^{3}$ of freshwater in 60 days. Over three continuous years this could deliver $10 \%-15 \%$ of the observed Labrador Sea freshwater anomaly into the West Greenland Current.

\section{f. Shelfbreak front}

The continuity of the Baffin Island Current passing through western Davis Strait and the Labrador Current on the western margin of the Labrador Sea has been described by Lazier and Wright (1993). The transition of the flow following contours of $f / h$ from the Baffin Island shelf with depths of 400-600 $\mathrm{m}$ onto the Labrador shelf with depths of $\sim 200$ m means that water on the Labrador shelf, box $\mathrm{C}(\mathrm{b})$, is derived from the inshore side of the Baffin Island Current, while the remaining water moves offshore to the upper slope at the shelf break, box $\mathrm{C}(\mathrm{g})$. The front separating fresh shelf water with Arctic Water properties from saltier water offshore with North Atlantic water properties is located at the shelf break.

The data can resolve the quasi-decadal variations of the Labrador shelfbreak front. Following Lazier (1982), the data are partitioned into a grid (Fig. 8) with borders roughly parallel to the 1000-m isobath. For each box salinity data are averaged over time intervals of 196466, 1972-74, 1979-81, and 1984-86, which incorporate

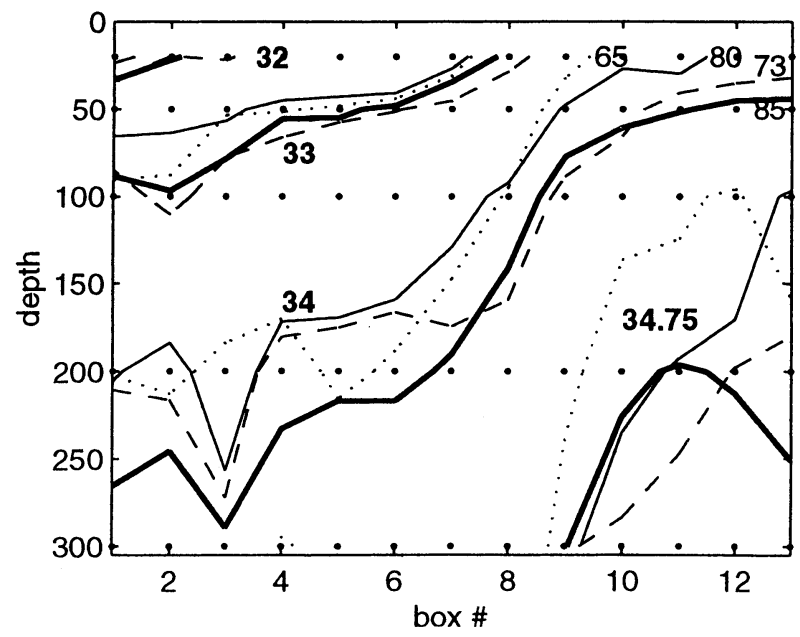

FIG. 9. The mean cross-shelf salinity structure defined by the 32 , 33,34 , and 34.75 isohalines for the year intervals of 1964-66 (dotted), 1972-74 (dashed), 1979-81 (thin), and 1984-86 (bold) and designated by $65,73,80$, and 85 , respectively. The dots indicate data locations from which isohalines are interpolated.

the extrema of the four dominant salty and freshwater anomalies on the Labrador margin.

Associated with these anomalies are significant variations in the salinity structure at the shelfbreak front (Fig. 9). The front, defined by the maximum cross-shelf density gradient (Fig. 10), is centered throughout the water column at box 8 , which incorporates the $400-$ $1000 \mathrm{~m}$ isobath interval in the slope region. This is the core of the baroclinic portion of the Labrador Current. Below $150 \mathrm{~m}$ there are no systematic changes in salinity associated with the freshwater anomalies. Likewise, over the shelf there are no significant variations in the upper $100 \mathrm{~m}$. A slight deepening of the 33 psu isohaline

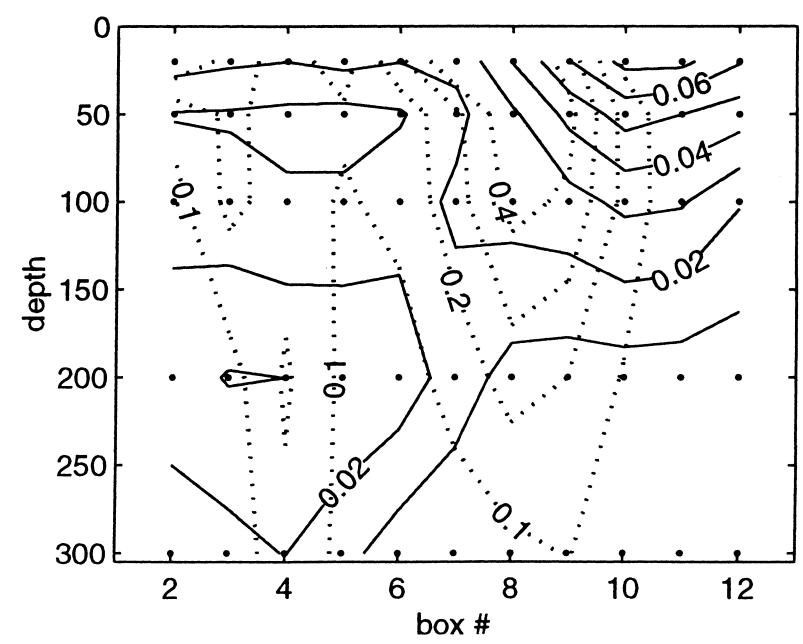

FIG. 10. Cross-shelf section of the salinity variance (solid) and horizontal density gradient (dotted). The variance calculated from the mean of the four 3-yr intervals is smoothed with a horizontal 1-2-1 filter. The density gradient is calculated from differencing the density of alternate boxes. 
near the front is perceptible, but the primary salinity change is a deepening of the isohalines in the upper 100 $m$ on the seaward side of the front. This is shown quantitatively by the isopleths of salinity variance in Fig. 10. The maximum salinity variance calculated for the quasidecadal salinity fluctuations in the 1960 s to 1980 s is in the upper water column centered at boxes 10-11 just seaward of the shelfbreak front. In contrast the position of the front, and hence the baroclinic portion of the Labrador Current over the slope, remained relatively constant and centered at box 8 during this period.

\section{g. Interior Labrador Sea}

The freshwater source for the Labrador Sea interior is from the margins. From consideration of the continuity of the eddy-induced overturning circulation associated with the annual cycle of the density field in the interior of the Labrador Sea, Khatiwala and Visbeck (2000) infer an offshore eddy velocity of approximately $0.5 \mathrm{~cm} \mathrm{~s}^{-1}$ in the upper $200 \mathrm{~m}$. This is sufficient to supply annually the $900 \mathrm{~km}^{3}$ of freshwater from the margin into the interior that is required to satisfy the annual cycle of the salinity budget in the interior of the Labrador Sea (Khatiwala 2000; Khatiwala et al. 2002). The quasi-decadal variation in the interior requires a freshwater accumulation of approximately $200 \mathrm{~km}^{3}$ $\mathrm{yr}^{-1}$. Thus, the observed quasi-decadal salinity variation in the interior of the Labrador Sea can be accounted for by a $20 \%$ change in the processes responsible for the mean annual cycle, that is, greater inflow from the margin or less convective mixing to depth.

\section{Discussion}

At some scale the forcing agent for the quasi-decadal fluctuations in the upper water column of the Labrador Sea must be the wind. Indeed, previous studies of SST and sea ice variability (Deser and Blackmon 1993; Deser et al. 2001) have attempted to relate these fluctuations to the NAO index (Fig. 11a), a measure of the largescale pressure gradient, and hence wind, in the North Atlantic. Likewise, the Arctic freshwater outflow through Fram Strait and the Canadian archipelago is thought to be wind-driven (Hilmer and Jung 2000). But given the advective time lag of freshwater anomalies from these sources there need not be any correlation of the arrival of this far-field signal with anomalies resulting from local wind forcing in the Labrador Sea.

\section{a. Local processes along the margin}

Advection certainly plays a role in the salinity anomalies observed in the Labrador Sea. The anomalies propagate cyclonically, as does the gyre circulation. An "upstream" signal for all three freshwater events is observed on the West Greenland margin and at Cape Farewell in the 1970s and 1990s, when there was sufficient
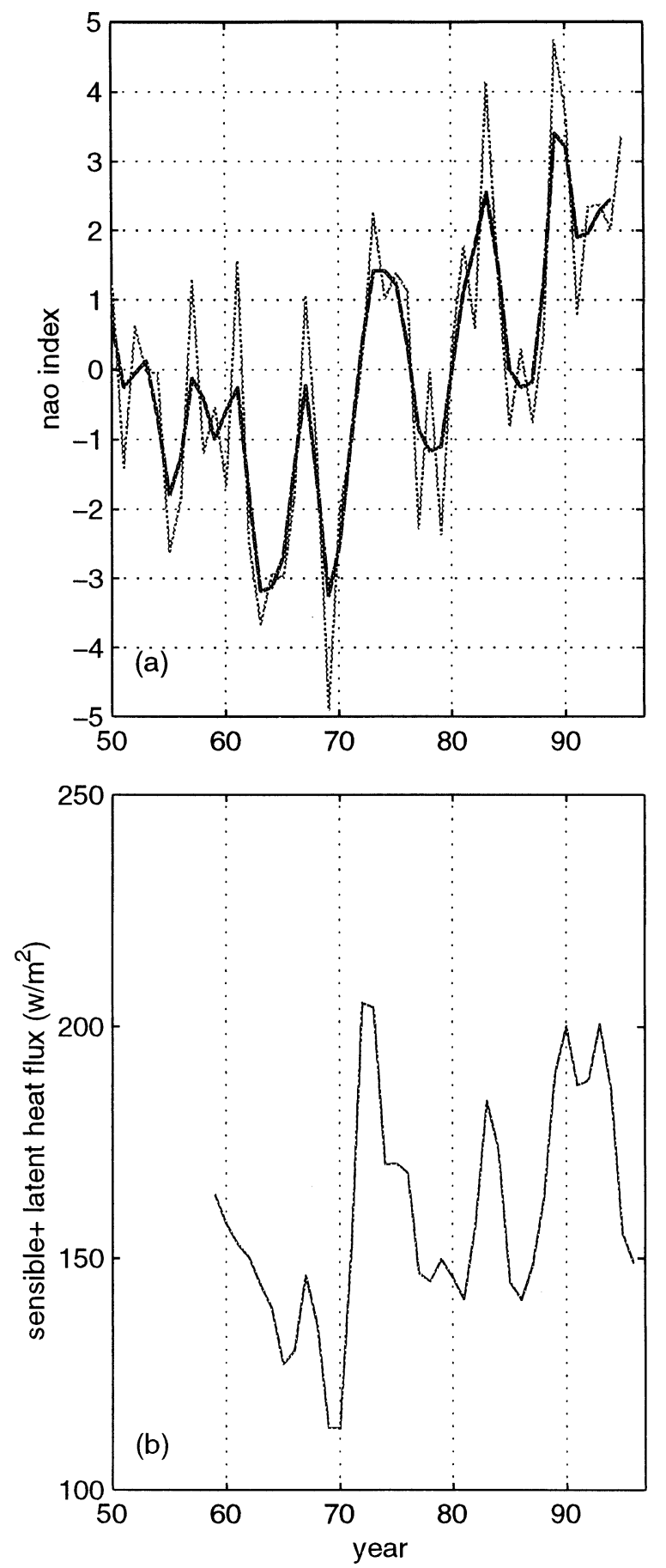

FIG. 11. (a) The time dependence of the NAO index: dotted line connects the mean Nov-Apr values assigned to the year of February; solid line is smoothed with a 1-2-1 filter. (b) The time dependence of the total NCEP buoyancy flux between Sep and Apr and assigned to the year of January in the vicinity of OWS Bravo, smoothed with a 1-2-1 filter.

data. However, the propagation speed is nearly an order of magnitude less than the Labrador Current speed. This indicates that the system is highly damped (Krahmann 

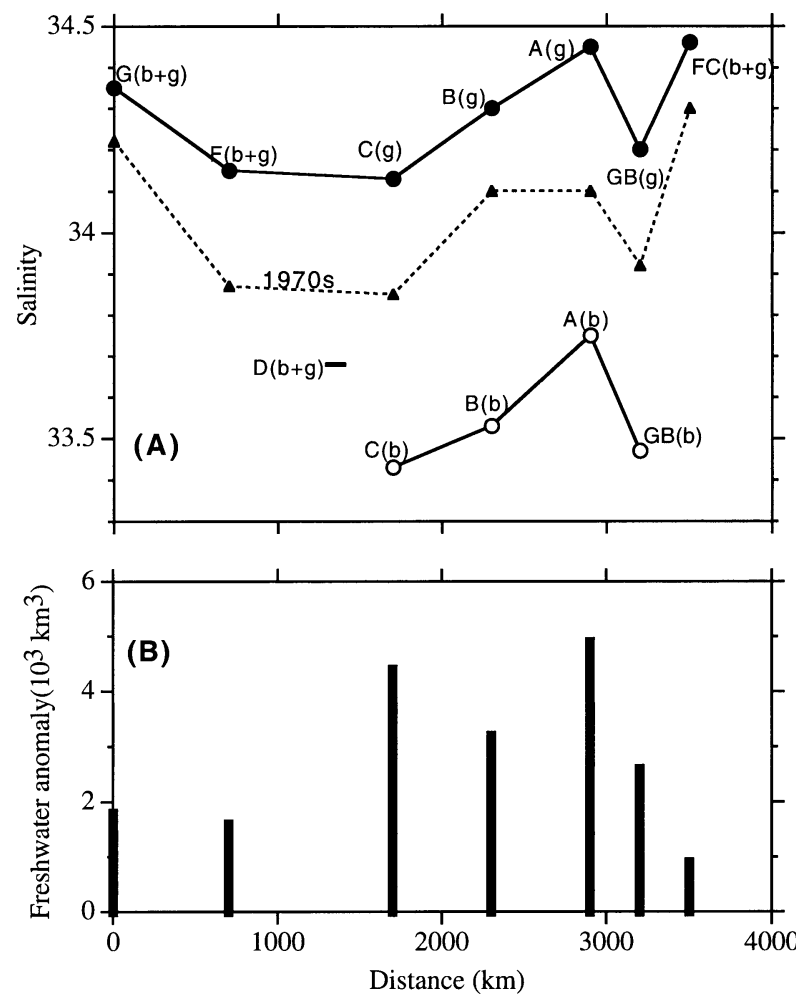

FIG. 12. (a) Mean salinity along the slope (solid dot) and shelf (open dot) as a function of distance from Cape Farewell. For dots labeled $(b+g)$ the shelf and slope data are combined. Mean salinity of the Davis Strait outflow is indicated by the short horizontal line. Also shown (dashed line) is the salinity of the 1970s anomaly. (b) The volume of the freshwater anomaly (taken from Table 2) for the 1970s event as a function of distance from Cape Farewell.

et al. 2001) and that the propagating anomaly is strongly modified by local processes.

There is other evidence of the effects of local processes and freshwater sources. For instance, there is the nearly decade-long freshening event observed at $\mathrm{E}(\mathrm{b}+$ $\mathrm{g}), \mathrm{F}(\mathrm{b}+\mathrm{g}), \mathrm{C}(\mathrm{g})$, and $\mathrm{B}(\mathrm{g})$ that began in the early 1960s. This precedes the GSA, which was first detected as freshening north of Iceland in 1964 (Malmberg 1973). Although this Labrador Sea freshening culminates in the GSA on the Labrador margin in 1972, it could not have been initiated by the Greenland Sea event. There must be a contribution from a local freshwater source.

The freshwater anomalies are modified as they propagate in the Labrador Sea gyre. The changes for the GSA event in the 1970s are illustrated in Fig. 12. There is an alongshelf variation in the mean salinity (Fig. 12a) on both the shelf and slope regions with a minimum at box $\mathrm{C}$. This is the location of the largest freshwater input, that is, the outflow of Baffin Bay whose mean salinity is given by $\mathrm{D}(\mathrm{b}+\mathrm{g})$, into the Labrador Sea. The salinity of the 1970s GSA as it propagates around the Labrador Sea changes in the same way, suggesting that the anomaly is not a simple external intrusion of

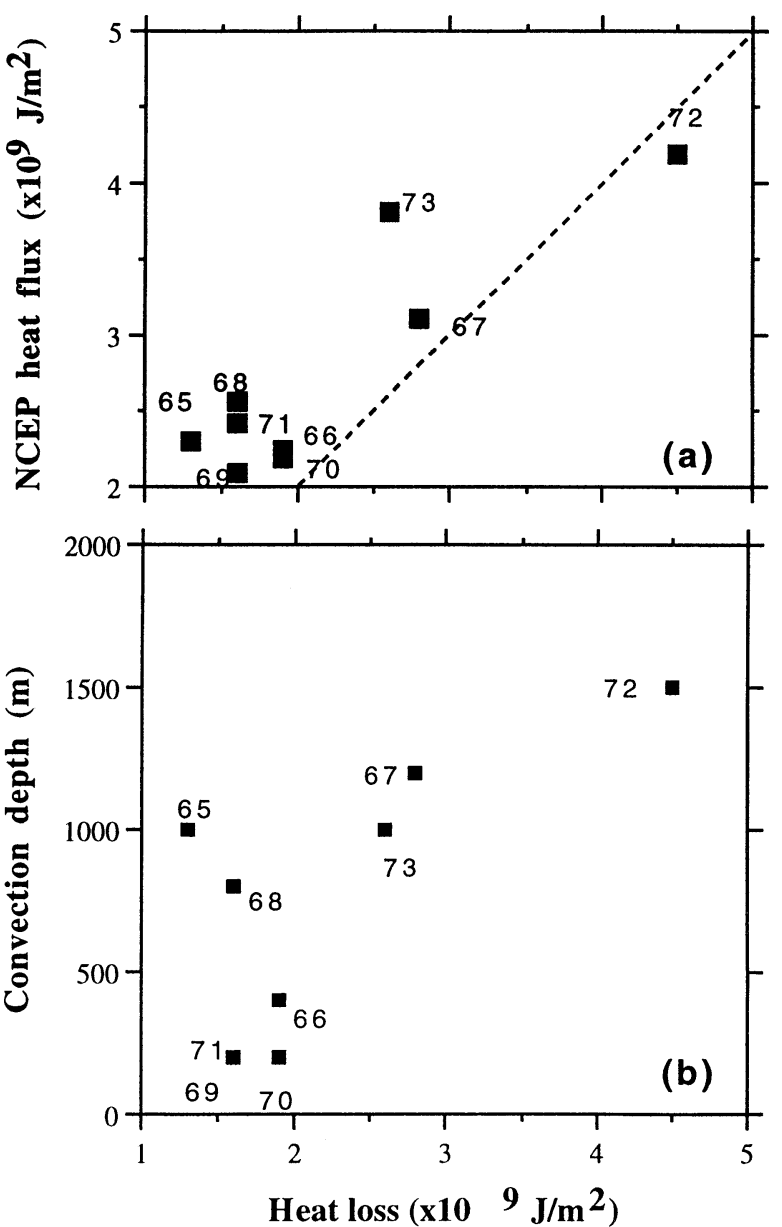

FIG. 13. (a) Heat flux $\left(\times 10^{9} \mathrm{~J} \mathrm{~m}^{-2}\right)$ at OWS Bravo for individual years (winter total assigned to Jan) 1965-73: the integrated 0-1500$\mathrm{m}$ water column temperature change (from Lazier 1980) vs NCEP surface flux. (b) Depth of convective mixing at OWS Bravo for the same years vs heat loss calculated from the integrated $0-1500-\mathrm{m}$ water column temperature change (from Lazier 1980).

water with anomalous properties but involves continuous modulation by local mixing processes.

The magnitude of the freshwater anomaly also changes in the course of its propagation around the Labrador Sea (Fig. 12b). Between West Greenland and the Labrador margin it approximately doubles. This would suggest an additional input in the vicinity of the Davis Strait outflow. The decrease at $\mathrm{FC}(\mathrm{b}+\mathrm{g})$ is due to the split in the flow at the northeast corner of Grand Banks, with most passing south through Flemish Pass and approximately 20\% flowing east along the North Flemish Cap (Loder et al. 1998).

\section{b. Convective mixing in the interior}

The role of local processes in generating the observed quasi-decadal fluctuations is more clear in the interior of the Labrador Sea. Associated with a positive NAO anomaly is an increased wind stress and, hence, in- 

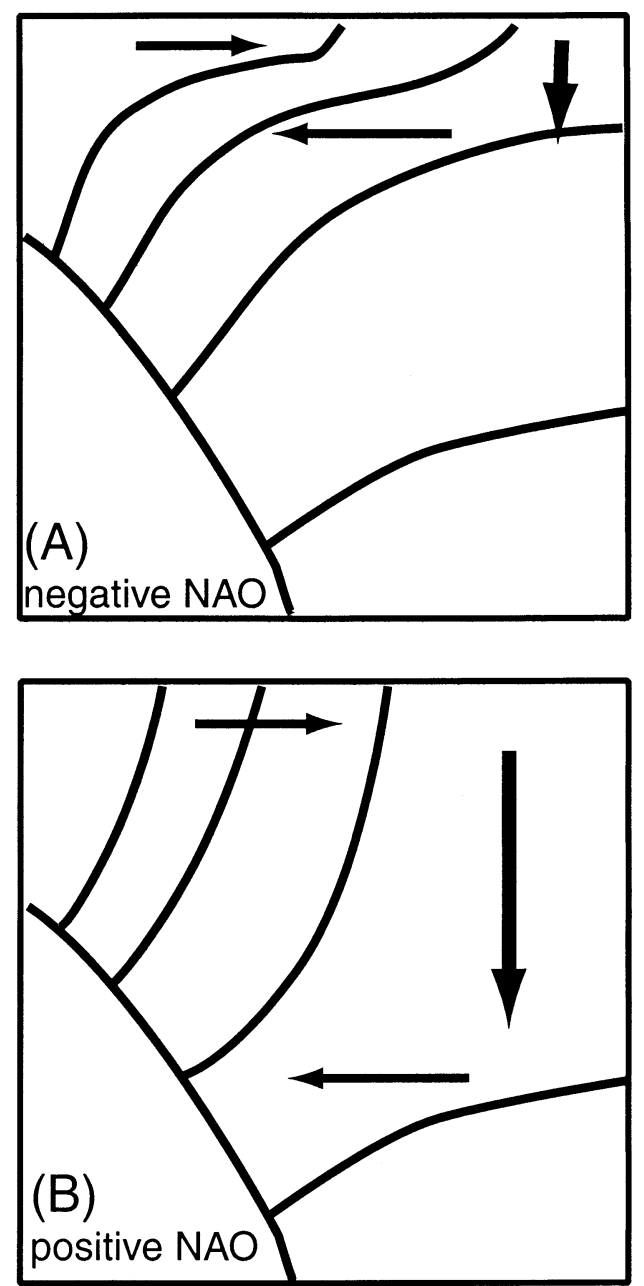

FIG. 14. Schematic of the isohalines across the Labrador slope region to illustrate the effect of variations in convective mixing for (a) weak wind/negative NAO and (b) strong wind/positive NAO. Horizontal arrows represent the eddy flux circulation; vertical arrows indicate the depth of convective mixing.

creased latent and sensible heat flux (Fig. 11b). The termination of the freshwater anomaly in the upper water column in 1972 and 1984 coincides with these sharp increases in the surface wind and hence the buoyancy fluxes. Analysis of the 1963-73 OWS Bravo data by Lazier (1980) illustrates this process. For these years the water column heat loss integrated to $1500 \mathrm{~m}$ (see Table 1 in Lazier 1980) roughly corresponds to the NCEP heat flux in the vicinity of OWS Bravo (Fig. 13a). In turn the depth of convective mixing correlates with this heat flux (Fig. 13b); both are greatest in 1972 . For a given heat flux the depth of convective mixing is modulated by the stratification. This is illustrated by the shallow mixing during 1969-71, when the stratification is high as the freshwater anomaly accumulates in the interior, in contrast to deeper mixing in 1965 and 1968 when the upper water column salinity was greater. Thus, the freshwater anomalies in the interior of the Labrador
Sea are the result of a gradual accumulation of freshwater derived from the margin that are then mixed to depth when surface buoyancy fluxes are sufficiently large to initiate deep convection.

\section{c. Labrador Current variation}

Along the margin of the Labrador Sea the processes responsible for the quasi-decadal salinity fluctuations and their connection with the NAO are less obvious. Since the salinity fluctuations are greatest over the upper slope region, it had been suggested that they arise from changes in the Labrador Current speed (Reverdin et al. 1997).

Fluctuations of the Labrador Current have been studied in detail. Lazier and Wright (1993) show that the annual cycle, with an amplitude of approximately $5 \mathrm{~Sv}$, is derived from the larger steric height variations over the shelf than offshore. They estimate that approximately $70 \%$ of the freshwater responsible for this annual steric height change on the Labrador shelf is supplied by the Baffin Island Current.

The processes responsible for the interannual variations of this baroclinic transport appear to be different. Analysis of the interannual variation of the baroclinic pressure gradient along the Seal Island section by Myers et al. (1989) shows that the baroclinic transport of the Labrador Current in the upper $100 \mathrm{~m}$ is negatively correlated with the NAO; that is, the southward transport diminishes during positive freshwater anomalies. The geostrophic transport over the slope calculated from the sections shown in Fig. 9 is consistent with this conclusion and suggests that the variations are approximately $30 \%$ of the mean and confined to the upper $100 \mathrm{~m}$.

The Labrador Current has a significant barotropic component. Combining current meter data with geostrophic calculations Lazier and Wright (1993) show that the barotropic component nearly tripled the total transport. Combining TOPEX/Poseidon altimeter data with WOCE hydrographic data Han and Tang (1999, 2001) are able to partition the total transport into barotropic, the bottom current integrated through the water column, and the baroclinic, the residual, components. They find interannual variations in the Labrador Sea gyre of approximately $7 \mathrm{~Sv}$, which is comparable to the seasonal range. They also show that the total and barotropic transport variations of the Labrador Current for the years 1993-98 are out of phase with the NAO; that is, there is stronger flow to the south (negative flux) for positive NAO anomalies. The baroclinic transport is slightly smaller and out of phase with the barotropic transport so it diminishes with a positive NAO anomaly consistent with Myers et al. (1989). They attribute this correlation of the NAO with the barotropic flow to the increase in the large-scale wind stress curl driving a stronger subpolar gyre, as modeled by Greatbach and Goulding (1989), during a positive NAO anomaly. 


\section{d. Convective mixing along the margin}

Since the location of the maximum quasi-decadal salinity fluctuations is actually located on the seaward side of the Labrador Current (Fig. 10), they are not likely to be the direct consequence of changing advection of freshwater. Instead, we propose that they are due to variability in the surface accumulation and downward flux of freshwater by the combined action of lateral transfer from the margin and convective mixing. The depth of convection is controlled by the competing effects of stratification, due to the accumulated freshwater, and surface buoyancy flux, a function of the wind (e.g., NAO).

This process is illustrated in the schematic diagram in Fig. 14. During periods of weak convection (negative NAO) freshwater accumulates offshore of the front near the surface. Weaker winds limit winter convection to approximately $100 \mathrm{~m}$, confining the freshwater to the upper water column and increasing the stratification. This positive feedback will increase the freshwater accumulation until strong surface buoyancy flux (positive NAO) initiates deep convection. This mixes the freshwater to depth, increasing the salinity at the surface and decreasing it at depth. Out-of-phase quasi-decadal salinity fluctuations at depth are observed in the Labrador Sea interior. Along the margin fluctuations at depth are not readily detected, presumably because of the higher noise level arising from eddy motions and the larger lateral salinity gradients there.

The lateral transfer of freshwater is due to the eddyinduced circulation arising from baroclinic instability proposed by Khatiwala and Visbeck (2000). For the purpose of our scenario we will assume this flux to be roughly constant. The accumulation of freshwater could be triggered by any freshwater anomaly, either local or advected from an upstream source or a decrease in the air-sea buoyancy flux. As the freshwater accumulation increases, it requires an even greater surface buoyancy flux to initiate deep convection. The positive NAO and corresponding large buoyancy flux events in 1973 and 1984 (Fig. 11) initiated deep convection, while the one in 1967 did not.

\section{Conclusions}

All available salinity data in the Labrador Sea region have been analyzed to investigate the quasi-decadal salinity fluctuations in the upper water column, which in the 1970's is identified as the GSA. The objective was to test some of the prevailing ideas about the freshwater sources and the forcing responsible for this variability. Although the Labrador Current is a segment of the North Atlantic subpolar gyre, the Labrador Sea is not a simple conduit for salinity anomalies originating in the East Greenland Current. Also, the salinity fluctuations over the slope are not a simple reflection of salinity variations on the adjacent shelf. Instead, there is an interplay of local and remote processes that complicates the interpretation of the observed salinity variations.

Although advection is clearly a factor, the anomaly propagation is cyclonic as is the gyre circulation, there is evidence that the anomaly is modulated by local water exchange along the margin. The propagation speed is nearly an order of magnitude less than the advection speed, an indicator of a highly damped system (e.g., Krahmann et al. 2001). The along-margin variation of the salinity anomaly is similar to that of the mean salinity. The volume of the anomaly increases on the Labrador margin. The maximum salinity fluctuations are on the seaward edge of the core of the Labrador Current.

The freshwater sources are both local and upstream. The decadal freshening trend beginning in 1962 along the northwest margin of the Labrador Sea could not have originated from the East Greenland freshwater event in 1964 that presumably initiated the GSA. It is likely that much of the freshwater associated with the anomalies in the Labrador Sea is derived by eddy flux from the margin. The outflow through the western side of Davis Strait, the dominant freshwater source of the Labrador Sea, has sufficient volume to account for much of the observed anomaly. This outflow can be both fresher seawater or sea ice that subsequently melts. Freshening events tend to occur during weak NAO conditions. Once an accumulation of freshwater in the upper water column is initiated it continues until it is dispersed by deep convective mixing forced by a sufficiently large buoyancy flux associated with a positive NAO.

The quasi-decadal fluctuations in the Labrador Sea during the 1960s to 1990s appear to be the result of both local and remote forcing. The accumulation of freshwater, greatest over the slope region but extending throughout the interior, is initiated by shallow convection due to a combination of weak winds and local or upstream freshwater flux anomalies, and thus there can be local variations in their timing. They intensify due to the positive feedback with increasing stratification. The termination of the freshwater anomaly in the upper water column throughout the Labrador Sea is the result of deep convection forced by strong winds, that is, a positive NAO event.

The density changes associated with the quasi-decadal $T / S$ variation fluctuations in the Labrador Sea are distinctly different from those observed in the central North Atlantic subpolar gyre (Houghton 1996; Reverdin et al. 1997). In the Labrador Sea the fluctuations are diapycnal and in $T / S$ space are oriented along the mixing curve connecting Arctic and North Atlantic Water types. Farther east, starting at Flemish Pass $\left(47^{\circ} \mathrm{N}, 47^{\circ} \mathrm{W}\right)$, the fluctuations become isopycnal. This difference is consistent with our proposed mechanism in which salinity fluctuations in the Labrador Sea are generated primarily by variations in the strength of convective mixing.

Acknowledgments. The technical assistance of Cheng Ho and the critical but constructive suggestions by the 
anonymous reviewers are gratefully acknowledged. The work was supported by NOAA Grant NA86GP0363.

\section{REFERENCES}

Agnew, T., 1993: Simultaneous winter sea ice and atmospheric circulation anomaly patterns. Atmos.-Ocean, 31, 259-280.

Belkin, I. M, S. Levitus, J. I. Antonov, and S.-A. Malmberg, 1998: "Great Salinity Anomalies" in the North Atlantic. Progress in Oceanography, Vol. 41, Pergamon, 1-68.

Cayan, D. R., 1992: Latent and sensible heat flux anomalies over the northern oceans: Driving the sea surface temperature. J. Phys. Oceanogr., 22, 859-881.

Chapman, W. L., and J. E. Walsh, 1993: Recent variations of sea ice and air temperatures in high latitudes. Bull. Amer. Meteor. Soc., 74, 33-47.

Cuny, J., P. B. Rhines, P. P. Niiler, and S. Bacon, 2002: Labrador Sea boundary currents and the fate of the Irminger Sea Water. $J$. Phys. Oceanogr., 32, 627-647.

Deser, C., and M. L. Blackmon, 1993: Surface climate variations over the North Atlantic during winter. J. Climate, 6, 1743-1753.

- M. Timlin, and G. Reverdin, 2001: Decadal variations in Labrador Sea ice cover and North Atlantic sea surface temperature. J. Geophys. Res., in press.

Dickson, R. R., J. Meincke, S. A. Malmberg, and A. J. Lee, 1988: The "Great Salinity Anomaly" in the northern Atlantic 1968 1982. Progress in Oceanography, Vol. 20, Pergamon, 103-151.

_ J. Lazier, J. Meincke, P. Rhines, and J. Swift, 1996: Long-term coordinated changes in the convective activities of the North Atlantic. Progress in Oceanography, Vol. 38, Pergamon, 241295.

Greatbatch, R. J., and A. Goulding, 1989: Seasonal variation in a linear barotropic model of the North Atlantic driven by the Hellerman and Rosenstein wind stress field. J. Phys. Oceanogr., 19, $572-595$

Han, G., and C. L. Tang, 1999: Velocity and transport in the Labrador Current determined from altimetric, hydrographic, and wind data. J. Geophys. Res., 104, 18 047-18 057.

$\longrightarrow$, and _- 2001: Interannual variations of volume transport in the western Labrador Sea based on TOPEX/Poseidon and WOCE data. J. Phys. Oceanogr., 31, 199-211.

Hilmer, M., and T. Jung, 2000: Evidence for a recent change in the link between the North Atlantic Oscillation and Arctic sea ice export. Geophys. Res. Lett., 27, 989-992.

Houghton, R. W., 1996: Subsurface quasi-decadal fluctuations in the North Atlantic. J. Climate, 9, 1363-1373.

Ice Climatology Services, 1992: Ice thickness climatology, 19611990 normals. Environment Canada Rep. En 5728/1961-1990, $477 \mathrm{pp}$.

Khatiwala, S. P., 2000: A tracer and modeling study of the Labrador Sea. Ph.D. thesis, Columbia University, 156 pp.
- and M. Visbeck, 2000: An estimate of the eddy-induced circulation in the Labrador Sea. Geophys. Res. Lett., 27, 22772280

_ P. Schlosser, and M. Visbeck, 2002: Rates and mechanisms of water mass transformation in the Labrador Sea as inferred from tracer observations. J. Phys. Oceanogr., 32, 666-686.

Krahmann, G., M. Visbeck, and G. Reverdin, 2001: Formation and propagation of temperature anomalies along the North Atlantic Current. J. Phys. Oceanogr., 31, 1287-1303.

Kushnir, Y., 1994: Interdecadal variations in North Atlantic sea surface temperature and associated atmospheric conditions. J. Climate, 7, 141-157.

Lazier, J. R. N., 1980: Oceanographic conditions at Ocean Weather Ship Bravo, 1964-1974. Atmos.-Ocean, 18, 227-238.

- 1982: Seasonal variability of temperature and salinity in the Labrador Current. J. Mar. Res., 40 (Suppl.), 341-356.

_ 1995: The salinity decrease in the Labrador Sea over the past thirty years. Natural Climate Variability on Decade-to-Century Time Scales, D. G. Martinson et al., Eds., National Academy Press, 295-302, 331

and D. G. Wright, 1993: Annual velocity variations in the Labrador Current. J. Phys. Oceanogr., 23, 659-678.

Loder, J. W., B. Petrie, and G. Gawarkiewicz, 1998: The coastal ocean off northeastern North America: A large-scale view. The Sea, A. R. Robinson and K. Brink, Eds., The Global Coastal Ocean, Vol. 11, John Wiley and Sons, 105-133.

Malmberg, S. A., 1973: Astand sjavar milli Islands og Jan Mayan, 1950-72. Aegir, 66, 146-148.

Marsden, R. F., L. A. Mysak, and R. A. Myers, 1991: Evidence for stability enhancement of sea ice in the Greenland and Labrador Seas. J. Geophys. Res., 96, 4783-4790.

Myers, R. A., J. Heilbig, and D. Holland, 1989: Seasonal and interannual variability of the Labrador Current and west Greenland Current. International Council for the Exploration of the Sea, Tech. Doc. CM1989/C:16, 18 pp.

Mysak, L. A., and D. K. Manak, 1989: Arctic sea-ice extent and anomalies, 1953-1984. Atmos.-Ocean, 27, 376-405.

, and R. F. Marsden, 1990: Sea-ice anomalies in the Greenland and Labrador Seas during 1901-1984 and their relation to an interdecadal Arctic climate cycle. Cimate Dyn., 5, 111-133.

Reverdin, G., D. Cayan, and Y. Kushnir, 1997: Decadal variability of hydrography in the upper North Atlantic, 1948-1990. J. Geophys. Res., 102 (C4), 8505-8531.

Trites, R. W., 1982: Overview of oceanographic conditions in NAFO Subareas 2, 3, and 4 during the 1970-79 decade. Northwest Atl. Fish. Organ., Sci. Counci. Stud., 5, 51-78.

Visbeck, M. H., H. Cullen, G. Krahmann, and N. Naik, 1998: An ocean model's response to North Atlantic Oscillation-like wind forcing. Geophys. Res. Lett., 25, 4521-4524.

Walsh, J. E., and D. H. Portis, 1999: Variations of precipitation and evaporation over the North Atlantic Ocean, 1958-1997. J. Geophys. Res., 104, 16 613-16 631. 